\title{
Editorial
}

\section{DO FLIES TRANSMIT LEPROSY?}

Exactly 3 years ago an editorial in Leprosy Review $(1972,43,165)$ posed the question "can arthropods transmit leprosy?", in reviewing the compelling experimental evidence from studies on arthropods (mosquito, bed bug and scabies mite) presented by Narayanan and his colleagues (Leprosy Review, 1972, 43, 188 and 194). They showed that these blood sucking insects fed on active lepromatous patients contained in their stomachs acid-fast bacilli (AFB) which failed to grow on conventional bacteriological media but multiplied when injected into mice, and their growth characteristics resembled those of Mycobacterium leprae. Therefore these arthropods potentially could be an intermediate host for the transmission of Myco. leprae. In the Review, however, it was pointed out that the number of Myco. leprae carried by an arthropod in a blood meal from a lepromatous patient would be very small compared to the vast numbers of bacilli shed in nasal secretions from the same patient. Therefore, potentially indirect transmission from an environment contaminated by such secretions would be a more likely and hazardous source. In the meantime, the studies by Davey and Rees (Leprosy Review, 1974, 45, 121) fully substantiate the potential hazard from these nasal secretions and that Myco. leprae in shed secretions in a dessicated state for 2-7 days, are still infectious in mice.

Now, in this number of Leprosy Review, J. G. Geater, working in Bhutan presents on the basis of simple but well conceived studies, the potential role of several common genera of flies in the transmission of leprosy. In this rapidly expanding field of studies on the modes of spread of Myco. leprae from infectious lepromatous patients, Geater's findings are of particular importance because they strongly implicate the fly as an intermediate insect carrier of Myco. leprae from shed and heavily infected nasal secretions direct to human contacts or by indirectly contaminating man's environment. With the limited facilities available to Geater in Bhutan his studies were based on three universally common genera of flies-Musca (housefly), Calliphora (blue-bottle) and Stomoxys (biting stable fly). He first showed that none of these representative genera caught in the wild state well away from the Leprosarium contained AFB in whole fly homogenates. However, when flies from these three genera were caged with a fresh specimen of heavily Myco. leprae infected nasal secretion from an untreated lepromatous patient, they were attracted to it and fed gluttonously upon it. Immediately following feeding the flies were separated and killed $1 \mathrm{~h}, 1,2$ and 3 days later. Each fly was dissected and pools of legs, mouth-piece, abdominal wall and stomach contents of each were homogenized, smears from homogenates prepared and stained with carbol fuchsin for AFB, after exposing to both acid and alcohol. The results showed that the flies in feeding on nasal secretions became 
heavily infected with AFB on their legs, mouth-pieces and abdominal walls as well as containing large numbers of AFB within their stomachs. The morphology of the AFB resembled $M y c o$. leprae and in particular, at all these sites, globus formation was common. This was the more or less universal finding $1 \mathrm{~h}$ after feeding, but a small proportion of the flies retained diminishing numbers of AFB at these various sites up to 3 days later; in particular, persisting AFB on their abdominal walls and within their stomach contents. Still more importantly, Geater showed that when the flies were caged with infected nasal secretion at one end of the cage and at the other end glass slides coated with albumin and with drops of sugar, while they preferred to feed on the nasal secretions they wandered from time to time and fed on both sites. After $2 \mathrm{~h}$ of such exposure the slides were removed and stained for AFB. Of 10 such slides examined only one was negative, the remaining 9 contained many AFB and in 6 slides globi were present. In a subsidiary experiment it was shown that flies allowed to feed upon ulcerated skin lesions of a highly positive untreated lepromatous patient also became similarly contaminated with AFB in all sites examined. Thus Geater has established that flies have, as is well known, a predilection for feeding upon human secretions and that, as in other situations, by so feed ing the outer surfaces of the flies become contaminated with the material and ipso facto with any contaminating micro-organisms. Likewise their stomachs are similarly contaminated and can be a source of spreading the contaminating microorganisms to wherever they next feed, by direct contact or by regurgitation from the digestive tract which occurs at the time of each feed. With the limitations available to Geater he was unable to use mouse inoculation to establish the AFB from the flies as Myco. leprae or their viability and it is of paramount importance that such studies now be undertaken. However, the studies of Davey and Rees would strongly suggest that Myco. leprae is robust enough to survive on flies for at least 2 days.

Thus, common species of flies must now be seriously considered as vehicles by which Myco. leprae could be readily carried from infected nasal or dermal secretions, either directly to another person, or indirectly to the environment at large. These studies on flies, as do those on nasal secretions increase significantly the ways by which leprosy could be spread. However, the eventual importance of all these studies will depend upon the actual mode of transmission of leprosy to man, which has still not been defined, although it is increasingly unlikely to be solely by close and prolonged skin-to-skin contact. Transmission of leprosy to man via the respiratory and gastrointestinal tracts must be reconsidered as they could be continuously exposed to Myco. leprae infeoted dust, water, food or feeding utensils. These possible routes of transmission do not lessen or exclude the importance of skin as a site of invasion by Myco. leprae. Moreover, since the mode of transmission of leprosy has still not been defined, it is important that all possible routes should be considered by those concerned with control and prevention of leprosy in the field and leprosy research. Until the mode of transmission of leprosy is defined, every effort should be made to minimize the risk of spread of Myco. leprae and Geater's findings indicate the importance of controlling fly populations in and around leprosy units. 